PERINATAL LESSONS FROM THE PAST

\title{
Erich Bracht (1882-1969) of Berlin and his "breech" manoeuvre
}

\section{P M Dunn}

Arch Dis Child Fetal Neonatal Ed 2003;88:F76-F77

Erich Bracht, a German gynaecologist, described in 1935 the manoeuvre named after him for delivering the frank breech with minimal interference. In spite of the reported success of his method, it received little attention in the United Kingdom or North America.

7

he following short biography of Erich Bracht derives from an account by Harold Speert.

"Erich Franz Eugen Bracht was born in Berlin, Germany, July 5, 1882, the son of a physician. After completing his formal medical education, he worked in the pathology laboratory of Aschoff in Freiburg, where he made an important contribution to the etiology and pathologic anatomy of rheumatic myocarditis. Having decided on a career in obstetrics and gynecology, he served as assistant to Menge in Heidelberg, then Pfannenstiel and Stöchel in Kiel, and finally Franz in Berlin. In 1922 Bracht was made extraordinary professor in the University of Berlin, and after Franz's death served for two years as acting director of the Charité Fravenklinik. In 1945 he was placed in charge of the Provincial Frauenklinik at Berlin-Neukölln, which was rebuilt after World War II into the city's largest hospital for women. He served also as consultant in obstetrics and gynecology in the US Occupation Forces in Berlin. He retired in 1955 and died in 1969. In addition to his professional activities, he was known as a collector of antique paintings and old Chinese and Japanese prints."

Bracht first described the manoeuvre that is named after him in a paper to the Berlin Obstetrical and Gynaecological Society on 4 October 1935. ${ }^{2}$ Then in May 1938 he showed a film of the procedure at the International Congress of Obstetrics and Gynecology in Amsterdam, and at the same time reported a series of 206 cases of breech delivery without a death. ${ }^{34}$ Although his technique was adopted and subjected to extensive trials in Germany, France, Spain, Holland, and South America, with fetal mortality figures suggesting its considerable superiority over more active management, the procedure seems to have been overlooked in the United Kingdom and the United States.

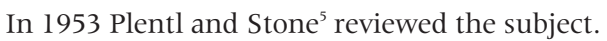
They started by pointing out that numerous statistical analyses from all over the world had established that the more the breech was manipulated and the earlier the manipulation was instituted, then the greater the fetal mortality and morbidity, to say nothing of maternal injuries. From this they argued that manipulation should be either avoided or reduced to a minimum whenever possible.

Plentl and Stone then compared the classical "assisted breech" with the "spontaneous" breech delivery. In the former there is downwards traction in the direction of the birth canal, rotation of the shoulders into an anteroposterior position with delivery of each arm, followed by manual or instrumental delivery of the head. In contrast, the cardinal points in the spontaneous delivery of the breech is the natural expulsive action producing an upward rotation of the baby's back around the symphysis of the mother, simultaneous delivery of the arms and shoulders in that order, and an attitude of extension facilitating the delivery of the head.

Next the authors described Bracht's simple, efficient, and effective method: the breech was allowed to deliver spontaneously to the umbilicus without push or pull. The knee-extended legs of

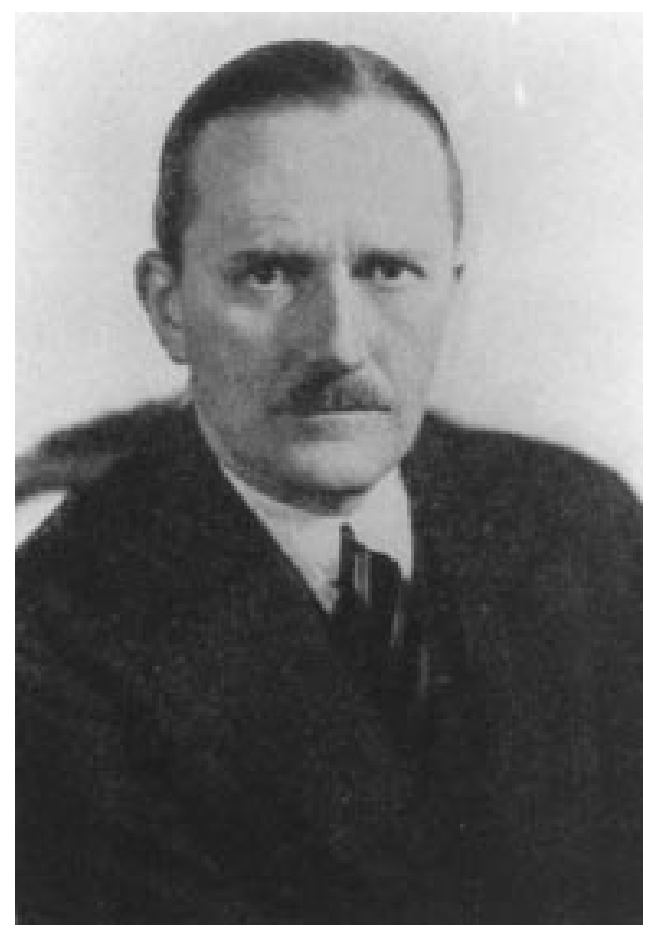

Figure 1 Erich Franz Bracht (1882-1969). 


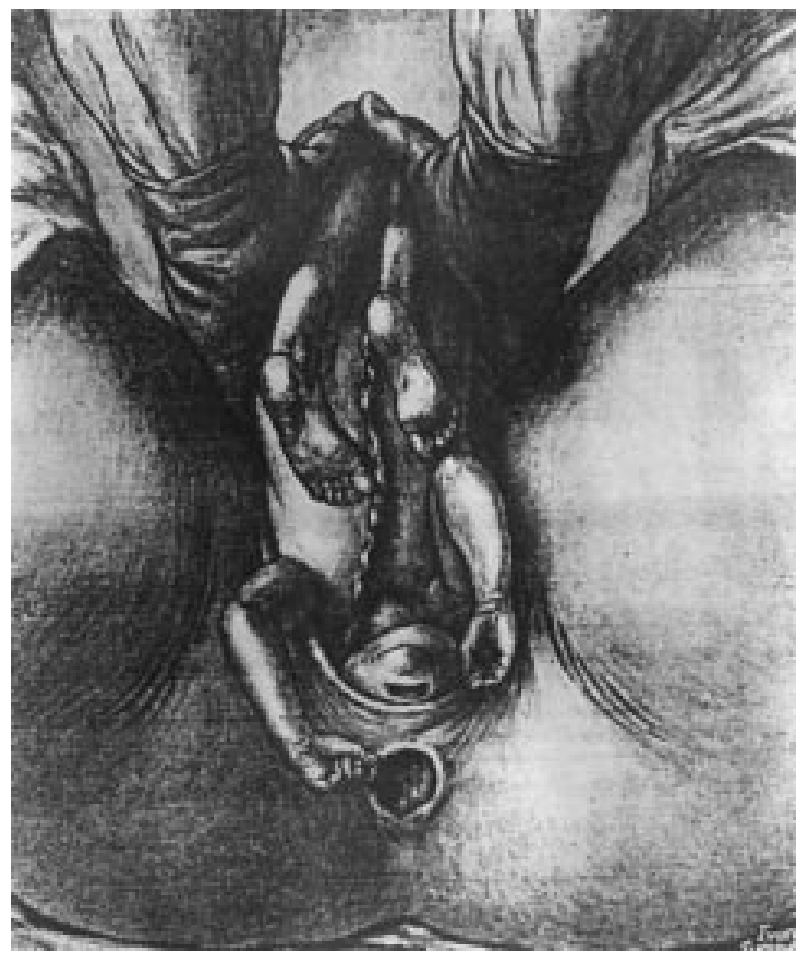

Figure 2 Bracht manoeuvre: delivery of the head. (By courtesy of the authors and editor of Obstetrical and Gynecological Survey). ${ }^{5}$

the flexed breech were not brought down. The body and extended legs were then grasped in both hands, with the fingers around the lower back and the thumbs around the posterior aspect of the thighs, while the upward and anterior rotation of the body was maintained. When the anterior rotation was nearly complete the baby's body was held, not pressed, against the mother's symphysis using only a force equivalent to the weight of that portion of the baby already born. The mere maintenance of this position, added to the uterine contractions and, if necessary, gentle suprapubic pressure by an assistant, allowed the baby's head to deliver spontaneously in full extension (fig 2). They noted that a reasonable degree of cooperation and minimum use of anaesthesia were essential prerequisites. In actual fact, in this method the obstetrician does little more than gravity would have achieved, had the woman been allowed to deliver in the natural upright position.

Plentl and Stone studied the results of more than 30 reports and seven doctors' theses on the use of the Bracht manoeuvre between 1938 and 1953. Their most stringent analysis led them to conclude that the perinatal mortality had been significantly reduced by the introduction of this manoeuvre, most certainly by one half and probably by more than a third of its former rate $(p<<0.01)$. As some 13000 babies were lost each year at that time in the United States as the result of breech delivery, they recommended that, after further rigorous testing, Bracht's manoeuvre should come into general use. Sadly, there is no evidence that their good advice was followed. The explanation may well rest in an observation made in their review:

"The art of waiting is a difficult one, and not many obstetricians have either the courage or the patience to sit idly by whilst the breech delivers spontaneously; this becomes even more difficult if the impatient obstetrician has a century of tradition as well as the words and writings of all contemporary teachers behind him. ${ }^{\prime 5}$

\section{REFERENCES}

1 Speert H. Erich Bracht and his maneuver for breech delivery. In: Obstetric and gynecologic milestones. New York: The Parthenon Publishing Co, 1996:562-3.

2 Bracht E. Zur manualhilfe bei beckenendlage. Ztschr Geburtsh Gynäk 1936;112:271.

3 Bracht E. Zur Behandlung der Steisslage. Handl Ing Cong v Verloskunde en Gynaecologie. 1938;2:93-4.

4 Bracht E. Zur Behandlung der Steisslage. Zentralb/ Gynäk 1938;62:1735

5 Plentl AA, Stone RE. The Bracht maneuver. Obstetrical and Gynecological Survey 1953;8:313-25. 